\title{
DESEMPENHO E DIGESTIBILIDADE DE NOVILHOS ZEBUÍNOS CONFINADOS RECEBENDO LEVEDURAS VIVAS E MONENSINA\#
}

\author{
GROWTH PERFORMANCE AND DIGESTIBILITY OF FEEDLOT ZEBU STEERS FED \\ YEAST AND MONENSIN
}

\begin{abstract}
Gomes, R.C. ${ }^{1 *}$, Antunes, M.T. ${ }^{1}$, Silva, S.L. ${ }^{1}$ e Leme, P.R. ${ }^{1}$
${ }^{1}$ Faculdade de Zootecnia e Engenharia de Alimentos. Universidade de São Paulo. Pirassununga, SP. Brasil. *gomes_rc@hotmail.com
\end{abstract}

\section{Palavras chave adicionais}

Aditivos alimentares. Bos indicus. Características de carcaça. Ionóforo. Saccharomyces cerevisiae.

\section{RESUMO}

Foi avaliado o efeito da adição de cultura de leveduras vivas (Saccharomyces cerevisiae, cepa 1026), da monensina e da combinação dos dois aditivos em dietas de alto concentrado, sobre as características de desempenho de novilhos confinados e sobre a digestibilidade aparente da dieta. Novilhos Nelore (339 kg PV, 20 meses de idade, $n=72$ ) foram alimentados por 84 dias com uma dieta basal (2,58 Mcal EM/kg MS, 14\% PB) sem aditivos (controle) ou suplementada com levedura $(0,6 \mathrm{~g}$ de Beef Sacc $\AA / \mathrm{kg}$ de matéria seca), monensina $(0,3 \mathrm{~g}$ de Rumensin $\AA / \mathrm{kg}$ de matéria seca) ou a adição de ambos aditivos para avaliar o desempenho em confinamento por meio da mensuração individual do consumo, ganho de peso e medidas de ultra-som da espessura de gordura subcutânea nos músculos Longissimus (12 ${ }^{\mathrm{a}}$ costela) e Biceps femoris. Outros quatro novilhos foram designados aleatoriamente aos tratamentos seguindo um delineamento em quadrado latino a fim de determinar os efeitos dos tratamentos sobre a digestibilidade aparente da matéria seca, proteína bruta, fibra em detergente neutro e ácido da dieta. Não houve efeitos dos aditivos sobre o consumo de matéria seca e na taxa de aumento da espessura de gordura subcutânea e em área do músculo Longissimus, entretanto, a levedura tendeu a diminuir o ganho de peso médio diário e aumentar a conversão alimentar $(p<0,10)$. Os coeficientes de digestibili-

"Projeto financiado por Fapesp.

\section{AdDITIONAL KEYWORDS}

Bos indicus. Carcass traits. Feed additives. Ionophore. Saccharomyces cerevisiae.

dade aparente das frações estudadas não foram influenciados pela adição dos aditivos na dieta $(p>0,10)$. A adição de leveduras vivas, monensina ou da combinação de ambos pode não ser importante sobre a terminação de bovinos de corte confinados com dieta de alto concentrado.

\section{SUMMARY}

The effect of adding live yeast culture (Saccharomyces cerevisiae, strain 1026), monensin or the combination of both additives to high grain diets on feedlot performance and digestibility of steers, was studied. Nellore steers ( $n=72,339 \mathrm{~kg} \mathrm{BW}, 20$ months-old) were fed for 84 days a basal ration (2.58 Mcal EM/kg DM, 14\% $\mathrm{CP})$ without additives (control), or with yeast culture (0.6 g Beef Sacc $₫ / \mathrm{kg} \mathrm{DM})$, monensin $(0.3 \mathrm{~g}$ Rumensin $₫ / \mathrm{kg}$ DM) or the combination of both additives to evaluate feedlot performance through individual measurements of dry matter intake, average daily gain and ultra-sound scanning of carcass subcutaneous fat thickness upon Longissimus (12 ${ }^{\text {th }}$ rib) and Biceps femoris muscle and rib eye area. Other four steers were randomly allotted to one of the treatments in a $4 \times 4$ latin square design in order to assess digestibility of dry matter, crude protein, neutral detergent fiber and acid detergent fiber fractions of the diet. There were no effects of additives on dry matter intake and rate of growth of carcass fat thickness and rib eye area. Yeast culture tended to decrease 
average daily gain and increase feed conversion $(p<0.10)$. Digestibility was not affected by treatments $(p>0.10)$. Supplementation of live yeast culture, monensin or the combination of both may not be important on finishing beef steers fed high grain diets in feedlot.

\section{INTRODUÇÃO}

O fornecimento de dietas com elevados teores de concentrados para bovinos de corte em confinamento permite o abate de animais jovens com acabamento de gordura adequado (Ribeiro et al., 2002, Leme et al., 2003). No Brasil, esta prática tem se tornado comum principalmente em regiões onde há grande disponibilidade de grãos, possibilitando aumento de desempenho e melhora nas características de carcaça de bovinos Nelore (Bos indicus), grupo genético base do rebanho brasileiro. Entretanto, a ingestão de grandes quantidades de carboidratos prontamente fermentescíveis pode aumentar a acidificação e a osmolaridade ruminal (Owens et al., 1998) causando uma depressão no desempenho (Preston, 1998).

Neste sentido, a adição do antibiótico monensina em dietas de confinamentos é utilizada como forma de inibir bactérias produtoras de ácido láctico (Dennis e Nagaraja, 1981), o que somado com uma freqüência potencialmente maior de refeições menores, podem diminuir os efeitos da alta produção de ácido no rúmen (Galyean e Rivera, 2003).

Contudo, a União Européia, um dos principais mercados para a carne brasileira, vem proibindo a utilização de ionóforos na alimentação animal por provavelmente causarem danos à saúde do consumidor (Anadón e Martínez-Larranãga, 1999) e promoverem a resistência de microrganismos a antimicrobianos (Wegener, 2003). Desta forma, surge a necessidade do estudo de aditivos alimentares alternativos que possam ser empregados nas condições brasileiras de produção e que auxiliem na minimização de distúrbios digestivos que dietas de alto concentrado podem causar.
Com este propósito, culturas de leveduras vivas têm sido investigadas na alimentação de ruminantes e têm demonstrado potencial em diminuir o risco de acidose ruminal e aumentar o desempenho animal por estimular o crescimento de bactérias utilizadoras de lactato (Nisbet e Martin, 1991), aumentar a taxa de degradação da fibra e também a ingestão de alimentos (Williams et al., 1991).

Visto tanto a levedura como a monensina modificarem o ambiente ruminal em direção à diminuição da concentração de ácido láctico, pode-se formular a hipótese que o emprego de ambos os aditivos em combinação poderia resultar em menor risco de surtos de acidose, com provável incremento no consumo de alimentos e desempenho animal. Caso isso seja verdadeiro, em países onde os ionóforos ainda são permitidos na nutrição animal, o uso desta estratégia beneficiaria principalmente a terminação de bovinos com dietas de alto concentrado.

Dado isso, o objetivo com este estudo foi o de avaliar o efeito da adição de leveduras vivas (Saccharomyces cerevisiae), da monensina e da combinação de ambos em dietas com alto teor de concentrado sobre o desempenho produtivo e a digestibilidade de novilhos Nelore (Bos indicus) em confinamento.

\section{MATERIAL EMÉTODOS}

O experimento foi desenvolvido entre os anos de 2006 e 2007 na Faculdade de Zootecnia e Engenharia de Alimentos da Universidade de São Paulo, FZEA/USP, em Pirassununga, SP, Brasil. O município de Pirassununga está situado a $21^{\circ} 59^{\prime}$ de latitude Sul e $47^{\circ} 26^{\prime}$ de longitude Oeste e a uma altitude de 634 metros. O clima é considerado subtropical tipo cwa Köppen (subtropical, com inverno seco e bem definido e verão quente e chuvoso).

Foram utilizados dois confinamentos experimentais. O primeiro possuía capacidade para 48 animais e era composto por 


\section{LEVEDURAS VIVASE MONENSINA PARA BOVINOS ZEBUÍNOS CONFINADOS}

quatro piquetes coletivos de $230 \mathrm{~m}^{2}$ cada, dispostos de 12 comedouros, nos quais eram instalados portões automáticos que possibilitaram a determinação do consumo individualizado. O segundo era composto por 24 baias individuais, parcialmente cobertas com telhas de zinco, dotadas de comedouro de alvenaria e bebedouros semiautomáticos.

Foram utilizados 72 novilhos da raça Nelore, com peso vivo (PV) médio inicial de $339,2 \pm 22 \mathrm{~kg}$ e idade de 20 meses. Os animais foram aleatoriamente designados a uma das baias individuais ou um dos piquetes. Após um período de adaptação de 21 dias, os tratamentos foram sorteados entre os animais. O sorteio ocorreu separadamente dentro do confinamento de baias individuais e dentro de cada piquete coletivo. Cada piquete coletivo recebeu 12 animais. Os piquetes coletivos e o confinamento de baias individuais foram considerados blocos dentro do delineamento experimental utilizado, num total de 5 blocos.

A dieta original do experimento (tabelas I e II) e os aditivos estudados foram oferecidos aos animais apenas do primeiro dia experimental em diante. Durante as três semanas de adaptação, a relação volumoso:concentrado aumentou de 60:40 na primeira, para 50:50 na segunda e para 40:60

Tabela I. Composição de ingredientes da dieta experimental com base na matéria seca (MS). (Ingredients composition of experimental diet, on a dry matter basis).

\begin{tabular}{lc}
\hline Ingredientes & \% na MS \\
\hline Milho grão seco & 39,7 \\
Farelo de soja 45\% & 6,8 \\
Casca de soja & 29,0 \\
Uréia & 1,0 \\
Núcleo mineral & 1,0 \\
Sulfato de amônia & 0,3 \\
Cloreto de potássio & 0,2 \\
Calcáreo calcítico & 1,0 \\
Bagaço de cana-de-açúcar in natura & 21,0 \\
\hline
\end{tabular}

Tabela II. Composição química da dieta experimental. (Chemical composition of experimental diet).

\begin{tabular}{lc} 
Matéria seca $^{1} 73,2 \%$ & \% na MS \\
\hline Extrato etéreo & 2,3 \\
Fibra em detergente neutro & 44,8 \\
Fibra em detergente ácido & 30,1 \\
Matéria mineral & 2,9 \\
Proteína bruta & 14,3 \\
Proteína degradável no rúmen & \\
Nutrientes digestíveis totais & \\
Energia metabolizável, Mcal/kg MS & 9,8 \\
& 71,3 \\
\end{tabular}

${ }^{1} \mathrm{Com}$ base na matéria natural. ${ }^{2} \mathrm{NRC}(1996) .{ }^{3} \mathrm{Calcu}-$ lado con la fórmula de Weiss et al. (1992).

na terceira semana. Tanto o volumoso, quanto o concentrado oferecidos durante a fase de adaptação foram os mesmos utilizados no período experimental. O volumoso utilizado foi o bagaço de cana-de-açúcar in natura, co-produto da indústria de açúcar e etanol, apresentando 54\% de matéria seca, $1,87 \%$ de proteína bruta, $93,3 \%$ de fibra em detergente neutro, $65,0 \%$ de fibra em detergente ácido, 0,01\% de extrato etéreo e 11,6\% de lignina em detergente ácido. A alimentação dos animais ocorreu uma vez ao dia, sempre por volta das 9 horas da manhã e as sobras foram retiradas e pesadas a cada dois dias.

Os tratamentos estudados foram:

Controle: dieta basal, sem adição de aditivos alimentares; levedura: dieta basal com adição de cultura de leveduras vivas (Saccharomyces cerevisiae); monensina: dieta basal com adição de monensina e monensina+levedura: dieta basal com adição de monensina e também de levedura.

A levedura (Saccharomyces cerevisiae, cepa 1026, Beef-Sacc ${ }^{\circledR}$, Alltech, Inc.) foi fornecida em $0,6 \mathrm{~g} / \mathrm{kg}$ de MS ingerida e a monensina na concentração de 30 ppm (0,3 g/kg de MS de Rumensin ${ }^{\circledR}$, Elanco, Inc.). O produto Rumensin ${ }^{\circledR}$ apresentava $10 \%$ de monensina sódica em sua composição. Em 
avaliação realizada no Laboratório de Microbiologia e Micotoxicologia de Alimentos da FZEA/USP, o produto Beef-Sacc ${ }^{\circledR}$ apresentou a concentração de $5,7 \times 10^{7} \mathrm{ufc} / \mathrm{g}$.

Para o fornecimento aos animais, os aditivos foram incorporados em fubá de milho para facilitar sua homogeneização na ração, de forma que a mistura (fubá + aditivo) fosse fornecida na concentração de $1,1 \%$ da dieta. A mistura era pesada, em sacos plásticos e homogeneizada manualmente na ração no momento do fornecimento no cocho de cada animal.

A quantidade de alimento e de aditivo fornecida foi reajustada a cada retirada de sobras. O fornecimento da ração total misturada foi de forma a se manter sobras entre 5 a $10 \%$ do montante oferecido. Semanalmente, amostras de sobras e do volumoso foram coletadas para determinação do teor de matéria seca.

Os animais foram pesados na entrada do confinamento, a cada 28 dias e ao final do experimento após jejum completo por 18 horas. O período experimental de avaliação foi de 84 dias, ocorridos após a fase de adaptação. O ganho médio diário (GMD) foi determinado como o coeficiente da estimativa da regressão do PV em função do tempo, determinado pelo procedimento REG do software estatístico SAS (SAS, 1998).

Em cada pesagem, foram mensuradas a espessura de gordura subcutânea e a área de olho do lombo, por ultra-sonografia, sob o músculo Longissimus dorsi, na região compreendida entre as $12^{\mathrm{a}}$ e $13^{\mathrm{a}}$ costelas do lado esquerdo do animal e também a cobertura de gordura sobre o músculo Biceps femoris (picanha).

Para isso, foi utilizado um aparelho de ultra-sonografia real time, marca Piemedical, modelo Scanner 200 VET, equipado com transdutor linear de 3,5 MHz e $18 \mathrm{~cm}$ de comprimento, acoplado a uma guia acústica. Óleo vegetal foi usado como acoplante acústico para permitir uma melhor transmissão e recepção das ondas de ultrasom e assim, obter-se imagens de melhor qualidade. As imagens foram armazenadas em um microcomputador e analisadas através do software Eview ${ }^{\circledR}$ (Pie Medical, Inc.).

Com o objetivo de avaliar o efeito dos aditivos estudados sobre a digestibilidade da matéria seca, da proteína bruta e das frações fibra em detergente neutro (FDN) e fibra em detergente ácido (FDA) da dieta, quatro novilhos Nelore (445 $\pm 13 \mathrm{~kg}$ PV), foram designados, seguindo um delineamento em quadrado latino $4 \times 4$, aos mesmos tratamentos utilizados no estudo de desempenho em confinamento. Os animais permaneceram alojados em galpão coberto, com piso cimentado e foram alimentados com a mesma dieta descrita anteriormente, uma vez ao dia, às 8 horas da manhã, de forma a permitir sobras de $5 \%$ em relação ao montante oferecido. A ingestão de alimentos foi medida diariamente com a retirada e pesagem do alimento não consumido. Os aditivos de interesse foram fornecidos da mesma forma e concentrações como descritas acima.

Por 19 dias em cada período experimental, foi permitido que os animais se adaptassem à dieta e então, nos dias 20 e 21, foram coletadas amostras de fezes para a determinação da produção fecal pelo marcador FDA indigestível, seguindo a metodologia descrita por Ítavo et al. (2002). Brevemente, amostras de fezes foram retiradas diretamente da ampola retal às 10 e 16 horas dos dias 20 e 21, respectivamente, de cada período experimental. Concomitantemente, amostras de sobras da alimentação foram coletadas para posteriores análises químicas. As concentrações de FDA indigestível nas fezes, alimentos e sobras foram determinadas através da incubação daqueles materiais, previamente secos $\left(55^{\circ} \mathrm{C}\right.$, 72 horas) e moídos (peneira de $1 \mathrm{~mm}$ ), no rúmen por 144 horas, com o auxílio de sacos de náilon. A incubação dos materiais no rúmen foi realizada em 2 novilhos Nelore fistulados, recebendo a mesma dieta experimental anteriormente descrita.

As determinações do teor de matéria 
seca, proteína bruta e extrato etéreo dos ingredientes da dieta, sobras e fezes (quando cabível) foram realizadas seguindo metodologia descrita por AOAC (1990). Para a determinação de FDN e FDA foi utilizada a metodologia descrita por Van Soest et al. (1991).

O efeito dos tratamentos sobre as características estudadas foi avaliado por análise de variância, através do procedimento GLM do software SAS (SAS, 1998) e as médias foram obtidas pela opção LSMEANS. Para as respostas referentes ao desempenho em confinamento foram incluídos no modelo estatístico os fatores de tratamento e bloco como efeitos fixos. Já para o estudo de digestibilidade aparente o modelo estatístico foi composto por tratamento, período e animal. Quando a análise de variância indicou a existência de diferenças entre os tratamentos, as respectivas médias foram comparadas pelo teste HSD-Tukey. Os efeitos dos fatores utilizados nos modelos foram considerados significantes ao nível de 5\% e probabilidades entre 5 e $10 \%$ foram discutidas como tendências.

\section{RESULTADOSEDISCUSSÃO}

Na tabela III são apresentadas as características de desempenho de novilhos confinados em função da adição da monensina e da levedura na dieta.

O PV inicial foi igual entre os grupos e os tratamentos não influenciaram o PV ao final do confinamento ( $p>0,10)$. Da mesma forma, o CMS em quilos por dia e em percentagem do PV foram estatisticamente iguais entre os tratamentos $(\mathrm{p}>0,10)$, mostrando que nenhum dos aditivos ou a combinação de ambos teve efeito sobre a ingestão de alimentos.

O ganho de peso médio diário tendeu $(\mathrm{p}<0,10)$ a ser diferente entre os tratamentos, sugerindo que animais suplementados com levedura apresentaram menor ganho de peso principalmente se comparado ao grupo controle, que não recebeu aditivos. A tendência de efeitos dos aditivos sobre o GMD provavelmente levou também a uma tendência $(p=0,051)$ da adição de levedura piorar a conversão alimentar.

Resultados semelhantes foram relatados por Mir e Mir (1994) que não observaram efeito da utilização de levedura sobre o ganho de peso, consumo de alimento e conversão alimentar de novilhos alimentados com dietas com alto teor de forragem ou com alto teor de grãos. Zinn et al. (1994) avaliaram a interação entre nível de forragem na dieta (10 ou $20 \%$ ) e monensina no desempenho de novilhos alimentados com dietas de alto concentrado e, assim como no presente estudo, não verificaram influencia da monensina sobre o ganho médio diário, consumo de alimentos e eficiência alimentar.

Da mesma forma, Adams et al. (1981) não encontraram diferenças entre novilhos suplementados com levedura ou monensina para ganho médio diário e conversão alimentar em relação ao grupo controle. Neste trabalho os autores também não observaram

Tabela III. Efeitos da adição de aditivos alimentares em dietas de alto concentrado sobre o desempenho em confinamento de novilhos Nelore. (Effects of adding feed additives to high grain diets on feedlot performance of Nellore steers).

\begin{tabular}{lcccccc}
\hline & \multicolumn{7}{c}{ Tratamentos } \\
& $\mathrm{C}$ & $\mathrm{L}$ & $\mathrm{M}$ & $\mathrm{M}+\mathrm{L}$ & $\mathrm{EPM}$ & $\mathrm{PE}$ \\
\hline PV inicial, kg & 338 & 341 & 342 & 337 & 5,03 & 0,44 \\
PV final, kg & 475 & 467 & 472 & 472 & 4,99 & 0,60 \\
GMD, kg/dia & 1,50 & 1,38 & 1,42 & 1,49 & 0,22 & 0,07 \\
CMS, kg/dia & 10,1 & 10,0 & 9,65 & 9,94 & 0,04 & 0,34 \\
CMS, \%PV & 2,50 & 2,48 & 2,37 & 2,46 & 0,04 & 0,22 \\
CMS/GMD & 6,8 & 7,3 & 6,9 & 6,8 & 0,19 & 0,05
\end{tabular}

C: controle; L: levedura; M: monensina.

EPM: erro-padrão da média; PE: probabilidade de um erro tipo I.

PV: peso vivo; GMD: ganho de peso médio diário; CMS: consumo de matéria seca; CMS/GMD: conversão alimentar. 
redução na ingestão de alimentos por animais recebendo monensina.

Em ovinos, o uso de levedura e monensina, sozinhos ou em combinação não afetou o consumo de alimentos (Garcia et al., 2000), o que está de acordo com os achados pelo presente trabalho.

Por sua vez, Williams et al.(1991), Wohlt et al. (1991) e Erasmus et al. (2005) demonstraram aumentos na produção de leite ou de seus componentes quando Saccharomyces cerevisiae foi adicionada a dietas para bovinos leiteiros. Os autores atribuíram como parte da causa deste fenômeno ao aumento da ingestão de matéria seca pela levedura, o que concorda com Adams et al. (1981) que verificaram maior ingestão de alimentos em novilhos suplementados com aditivo contendo leveduras vivas.

Restle et al. (2001) observaram menor consumo de matéria seca em vacas e novilhas confinadas com dietas contendo monensina, o que concorda com Goodrich et al. (1984) que indicam como um dos efeitos da monensina a depressão do consumo. Estes autores também relatam em sua revisão o aumento da eficiência alimentar com o uso do ionóforo em questão como sendo um dos seus principais efeitos. Entretanto no estudo de Restle e colaboradores, assim como na presente investigação, não foram observados efeitos da monensina sobre a conversão alimentar de vacas de corte.

A falta de efeitos dos aditivos estudados sobre o desempenho em confinamento também pode ser observada através da avaliação do crescimento dos componentes da carcaça por ultra-sonografia (tabela IV).

Não houve efeitos dos aditivos ( $\mathrm{p}>0,10)$ na taxa de deposição de gordura subcutânea sobre a região compreendida entre a $12^{\mathrm{a}} \mathrm{e}$ $13^{\text {a }}$ costelas, assim como sobre a garupa (músculo Biceps femoris). Também não foi verificado efeito dos aditivos sobre a velocidade de crescimento da área do músculo Longissimus dorsi ( $\mathrm{p}>0,10)$.
Tal fato sugere que é pouco provável que os aditivos estudados tenham algum efeito sobre as características de carcaça medidas ao abate e que traga benefícios no sentido de auxiliar o alcance de uma determinada cobertura de gordura desejada e no aumento do rendimento de porção comestível.

Os resultados encontrados neste trabalho, em relação ao crescimento dos componentes da carcaça estão de acordo com os achados por Greene (2002) que avaliou o efeito da adição de Saccharomy-

Tabela IV. Efeitos da adição de aditivos alimentares em dietas de alto concentrado sobre o ganho tecidual total e diário ${ }^{1}$ de novilhos Nelore medido por ultra-sonografia. (Effects of adding feed additives to high grain diets on ultra-sound total and daily tissue gain of Nellore steers).

\begin{tabular}{|c|c|c|c|c|c|c|}
\hline & & Trat & ament & & & \\
\hline & C & L & M & $M+L$ & EPM & PE \\
\hline GAOL, cn & & & & & & \\
\hline total & 16,6 & 14,5 & 15,5 & 15,8 & 0,47 & 0,39 \\
\hline diário & 0,20 & 0,18 & 0,19 & 0,19 & 0,01 & 0,47 \\
\hline GEGS, mm & & & & & & \\
\hline total & 4,44 & 4,04 & 4,29 & 3,88 & 0,20 & 0,77 \\
\hline diário & 0,05 & 0,05 & 0,05 & 0,05 & 0,01 & 0,95 \\
\hline GEGP, mm & & & & & & \\
\hline total &, 68 & 4,60 & 5,14 & 4,85 & 0,24 & 0,42 \\
\hline diário & 0,07 & 0,07 & 0,07 & 0,06 & 0,01 & 0,34 \\
\hline
\end{tabular}

C: controle; L: levedura; M: monensina.

EPM: erro-padrão da média; PE: probabilidade de um erro tipo I.

${ }^{1}$ Ganho tecidual total na carcaça determinado como a diferença entre as medidas realizadas no início e no fim do período de alimentação. Ganho tecidual diário foi obtido como o coeficiente angular da regressão linear ente as medidas de ultrasom e tempo de confinamento.

GAOL: ganho em área de olho de lombo; GEGS: ganho em espessura de gordura subcutânea sobre o músculo Longissimus dorsi; GEGP: ganho em espessura de gordura na garupa sobre o músculo Biceps femoris (picanha). 
ces cerevisiae (BIOSAF ${ }^{\circledR}, 8 \times 10^{9} \mathrm{ufc} / \mathrm{g}$ do produto) em dietas de alto concentrado para novilhas cruzadas, confinadas por 141 dias, e não observou efeito dos tratamentos para espessura de gordura subcutânea e área de músculo Longissimus dorsi.

Semelhantemente, Mir e Mir (1994) não verificaram efeito da levedura sobre a cobertura de gordura e área do músculo Longissimus em novilhos Hereford. Ainda, Morais et al. (1993) não verificaram efeito da monensina sobre a área do músculo Longissimus e espessura de gordura subcutânea de bovinos 3/4 Gir-Holandês alimentados com uma dieta à base de forragem em confinamento.

Na tabela V são apresentadas as digestibilidades aparentes da matéria seca, da proteína bruta, da fibra em detergente neutro e em detergente ácido em função dos aditivos estudados.

Não houve efeito da monensina, da levedura ou da sua combinação sobre a digestibilidade aparente das frações matéria seca, proteína bruta, FDN e FDA da dieta ( $>>0,10)$.

Mir e Mir (1994) relataram não haver efeito da adição de leveduras vivas em dietas baseadas em silagem de alfafa, silagem de milho ou em cevada (alto concentrado) sobre a digestibilidade da matéria seca, proteína bruta, FDN e FDA. Os autores verificaram apenas que a levedura aumentou a digestibilidade da proteína bruta de dietas a base de cevada.

Aumento na digestibilidade da proteína bruta também foi observado com o uso de leveduras em dietas para vacas em lactação (Erasmus et al., 1992). No trabalho citado, verificou-se ainda que o aditivo aumentou o coeficiente de digestibilidade da FDA da dieta.

A adição de leveduras vivas, de monensina e da combinação de ambos em dietas com relação volumoso:concentrado de 50:50 para ovinos, não teve efeito sobre a digestibilidade da matéria seca e da FDN (Garcia et al., 2000), concordando com o que foi observado na presente investigação.

Algumas hipóteses podem ser levantadas em relação à inexistência de efeitos dos aditivos estudados, nas condições do presente trabalho. A monensina tem apresentado grande potencial em melhorar a eficiência alimentar animal, contudo, existe uma considerável variabilidade em seus resultados (Goodrich et al., 1984). Aparentemente, o ionóforo apresenta resultados mais consistentes quando não há um correto balanceamento da dieta e o desempenho animal é baixo (Goodrich et al., 1984), ao contrário da situação obtida nesta investigação. Além disso, tem sido mostrado em alguns estudos com ionóforos indício de uma possível adaptação da microbiota ruminal (Richardson et al., 1976; Dennis et al., 1986; Johnson e Johnson, 1995; Arakaki et al., 2000). Ainda, bactérias ruminais provenientes de animais recebendo dieta exclusiva de forragem são mais sensíveis à monensina que aquelas de animais sob dietas ricas em concentrado, indicando que este ionóforo pode ter maior benefício no

Tabela V. Efeitos da adição de aditivos alimentares em dietas de alto concentrado sobre a digestibilidade aparente da matéria seca (DAMS), da proteína bruta (DAPB), da fibra em detergente neutro (DAFDN) e em detergente ácido (DAFDA), em novilhos Nelore. (Effects of adding feed additives to high grain diets on apparent digestibility of diet dry matter, crude protein, neutral detergent fiber and acid detergent fiber, in Nellore steers).

\begin{tabular}{lcccccc}
\hline \multicolumn{7}{c}{ Tratamentos } \\
& C & L & M & M+L & EPM & PE \\
\hline DAMS, \% & 62,9 & 56,6 & 60,8 & 63,7 & 2,45 & 0,83 \\
DAPB, \% & 64,4 & 61,8 & 62,1 & 66,9 & 2,53 & 0,85 \\
DAFDN, \% & 55,1 & 52,7 & 50,0 & 52,3 & 2,41 & 0,99 \\
DAFDA, \% & 61,8 & 58,4 & 56,1 & 59,1 & 2,62 & 0,97 \\
\hline
\end{tabular}

C: controle; L: levedura; M: monensina.

EPM: erro-padrão da média; PE: probabilidade de um erro tipo I. 
desempenho de bovinos em pastagens ou em dietas contendo elevado nível de volumoso em comparação àquelas ricas em concentrado (Lana e Russel, 2001).

Quanto à levedura, aumentos na digestibilidade da matéria seca, proteína bruta, matéria orgânica, FDN e FDA da dieta, no ganho de peso e melhora da conversão alimentar têm sido aliados à utilização de aditivos contendo Saccharomyces cerevisiae em dietas de alto concentrado para ovinos (Haddad e Goussous, 2005).

Também tem sido mostrado que aditivos microbianos podem beneficiar a nutrição de ruminantes com o aumento na taxa de degradação da fibra e por um maior fluxo de aminoácidos absorvíveis para o intestino (Martin e Nisbet, 1992), resultando em aumento na ingestão de alimentos (Wallace, 1994) provavelmente pelo aumento na degradação ruminal dos carboidratos fibrosos.

Os efeitos citados podem ser devidos, ao menos em parte, pela promoção de uma fermentação microbiana mais eficiente em um ambiente mais estável, uma vez que as leveduras estimulam bactérias que utilizam lactato e produzem propionato (Waldrip e Martin, 1993). O mesmo ocorre com a monensina, já que esta seleciona bactérias gram negativas favorecendo microrganismos produtores de propionato e inibindo os produtores de ácido láctico (Dennis et al., 1981).

Desta forma, aumentos em desempenho poderiam ser esperados, seja pelo uso da monensina, da levedura e ainda mais pela combinação de ambos, como decorrência do potencial dos aditivos estudados em proporcionar um $\mathrm{pH}$ ruminal mais estável, podendo evitar perdas em desempenho por distúrbios metabólico-digestivos como a acidose ruminal.

Propositalmente, este estudo procurou utilizar uma dieta com alto teor de concentrado a qual desafiasse o equilíbrio do ambiente ruminal dos animais, de uma forma na qual os aditivos pudessem apresentar o modo de ação indicado pela maioria dos trabalhos. Entretanto, apesar da dieta ser composta apenas por $21 \%$ de volumoso, uma proporção de $29 \%$ desta foi composta por casca de soja. Este alimento possui altos teores de FDN e FDA, porém baixo de lignina, resultando em coeficiente de digestibilidade in vitro da matéria seca maior até que 90\% (Quicke et al., 1959, citados por Ludden et al., 1995). Apesar de ser um alimento que é altamente fermentável no rúmen, este não promove uma acidificação tão acentuada do ambiente ruminal quanto o ácido láctico, produto da fermentação do amido, uma vez que o resultado da fermentação de carboidratos estruturais é o ácido acético, sabidamente um ácido fraco. Tal fato é comprovado pelo estudo de Grigsby et al. (1993) que verificaram um aumento linear no $\mathrm{pH}$ ruminal com o aumento da substituição do milho pela casca de soja no concentrado da dieta de novilhos.

Assim, a inexistência de efeito dos aditivos estudados sobre as características de desempenho, pode ser devido, ao menos em parte, à utilização de uma dieta que forneceu um alto teor de energia, visto os ganhos alcançados, mas que pode ter proporcionado um padrão de fermentação ruminal não limitante ao aproveitamento dos nutrientes.

Em resumo, apesar de serem largamente empregados na alimentação de bovinos de corte confinados, a monensina e culturas de leveduras vivas podem não apresentar efeitos benéficos sobre o desempenho em confinamento e qualidade de carcaça em animais recebendo dietas bem balanceadas. Sendo assim, seu uso pode ser dispensável na alimentação de bovinos de corte confinados, uma vez que representaria um custo adicional ao da dieta. O mesmo é verdadeiro para a estratégia de se combinar ambos aditivos. Mais estudos são necessários visando elucidar uma possível interação entre ingredientes e aditivos, o que pode ser uma das principais razões para a variabilidade de respostas encontradas pelos diferentes trabalhos realizados até então. 


\section{LEVEDURAS VIVASE MONENSINA PARA BOVINOS ZEBUÍNOS CONFINADOS}

\section{BIBLIOGRAFIA}

Adams, D.C., Galyean, M.L., Kiesling, H.E., Wallace, J.D. and Finkner, M.D. 1981. Influence of viable yeast culture, sodium bicarbonate and monensin on liquid dilution rate, rumen fermentation and feedlot performance of growing steers and digestibility in lambs. J. Anim. Sci., 53: 780-789.

Arakaki, L.C., Stahringer, R.C., Garret, J.E. and Dehority, B.A. 2000. The effects of feeding monensin and yeast culture, alone or in combination, on the concentration and generic composition of rumen protozoa in steers fed on low-quality pasture supplemented with increasing levels of concentrate. Anim. Feed Sci. Tech., 84: 121-127.

Anadón, A. and Martínez-Larrañaga, M.R. 1999. Residues of antimicrobial drugs and feed additives in animal products: regulatory aspects. Livest. Prod. Sci., 59: 183-198.

AOAC. 1990. Official Methods of Analysis. Association of Official Analytical Chemistis. Washington D.C.

Dennis, S.M. and Nagaraja, T.G. 1981. Effects of lasalocid or monensin on lactate-producing or using rumen bacteria. J. Anim. Sci., 52: 418426.

Dennis, S.M., Nagaraja, T.G. and Dayton, A.D. 1986. Effects of lasalocid, monensin and thiopeptin on rumen protozoa. Res. Vet. Sci., 41: 251-256.

Erasmus, L.J., Botha, P.M. and Kistner, A. 1992. Effect of yeast culture supplement on production, rumen fermentation, and duodenal nitrogen flow in dairy cows. J. Dairy Sci., 75: 3056-3065.

Erasmus, L.J., Robinson, P.H., Ahmadi, A., Hinders, R. and Garret, J.E. 2005. Influence of prepartum and postpartum supplementation of a yeast culture and monensin, or both, on ruminal fermentation and performance of multiparous dairy cows. Anim. Feed Sci. Tech., 122: 219239.

Galyean, M.L. and Rivera, J.D. 2003. Nutritionally related disorders affecting feedlot cattle. Can. J. Anim. Sci., 83: 13-20.

Garcia, C.C.G., Mendoza, M.G.D., Gonzáles, M.S., Cobos, P.M., Ortega, C.M.E. and Ramirez, L.R. 2000. Effect of a yeast culture (Saccharomyces cerevisiae) and monensin on ruminal fermen- tation and digestion in sheep. Anim. Feed Sci. Tech., 83: 165-170.

Goodrich, R.D., Garrett, J.E., Gast, D.R., Kirick, M.A., Larson, D.A. and Meiske, J.C. 1984. Influence of monensin on the performance of cattle. J. Anim. Sci., 58: 1484-1498.

Greene, W. 2002. Use of Saccharomyces cerevisiae in beef cattle. Simposio Goiano sobre Manejo e Nutrição de Bovinos de Corte, 4. Anais... CBNA. Goiânia. pp. 79-96.

Grigsby, K.N., Kerley, M.S., Paterson, J.A. and Weigel, J.C. 1993. Combinations of starch and digestible fiber in supplements for steers consuming a low-quality bromegrass hay diet. J. Anim. Sci., 71: 1057-1064.

Haddad, S.G. and Goussous, S.N. 2005. Effect of yeast culture supplementation on nutrient intake, digestibility and growth performance of Awassi lambs. Anim. Feed Sci. Tech., 118: 343-348.

Ítavo, L.C.V., Valadares Filho, S.C., Silva, F.F., Valadares, R.F.D., Paulino, M.F., Ítavo, C.C.B.F. e Moraes, E.H.B.K. 2002. Comparação de indicadores e metodologia de coleta para estimativas de produção fecal e fluxo de digesta em bovinos. Rev. Bras. Zootecn., 31: 18331939.

Johnson, K.A. and Johnson, D.E. 1995. Methane emissions from cattle. J. Anim. Sci., 73: 24832492.

Lana, R.P. e Russel, J.B. 2000. Efeitos da monensina sobre a fermentação e sensibilidade da bactérias ruminais de bovinos sob dietas ricas em volumoso ou concentrado. Rev. Bras. Zootecn., 30: 254-260.

Leme, P.R., Silva, S.L., Pereira, A.S.C., Putrino, S.M., Lanna, D.P.D. e Nogueira Filho, J.C.M. 2003. Utilização do bagaço de cana-de-açúcar em dietas com elevada proporção de concentrados para novilhos Nelore em confinamento. Rev. Bras. Zootecn., 32: 1786-1791.

Ludden, P.A., Cecava, M.J. and Hendrix, K.S. 1995. The value of soybean hulls as a replacement for corn in beef cattle diets formulated with or without added fat. J. Anim. Sci., 73: 2706-2711.

Martin, S.A. and Nisbet, D.J. 1991. Effect of directfed microbials on rumen microbial fermentation. J. Dairy Sci., 75: 1736-1744. 
Mir, Z. and Mir, P.S. 1994. Effect of the addition of live yeast (Saccharomyces cerevisiae) on growth and carcass quality of steers fed highforage or high grain diets and on feed digestibility and in situ degradability. J. Anim. Sci., 72: 537545.

Morais, C.A.C., Fontes, C.A.A. e Lana, R.P. 1993. Influência da monensina sobre o rendimento de carcaça e de seus cortes básicos e outras características, em bovinos castrados e não castrados. Rev. Bras. Zootecn., 22: 72-80.

NRC. 1996. National Research Council. Nutrient requirements of beef cattle. National Academy Press. Washington, DC.

Nisbet, D.J. and Martin, S.A. 1991. Effect of a Saccharomyces cerevisiae culture on lactate utilization by the ruminal bacterium Selenomonas ruminantium. J. Anim. Sci., 69: 4628-4633.

Owens, F.N., Secrist, D.S., Hill, W.J. and Gill, D.R. 1998. Acidosis in cattle: a review. J. Anim. Sci., 76: 275-286.

Preston, R.L. 1998. Management of high concentrate diets in feedlot. Simpósio sobre Produção Intensiva de Gado de Corte, 1. Anais... CBNA. Campinas. pp. 82-91.

Quicke, B.V., Bentley, O.G., Scott, H.W., Johnson, R.R. and Moxon, A.L. 1959. Digestibility of soybean hulls and flakes and the in vitro digestibility of cellulose in various milling byproducts. J. Dairy Sci., 42: 185-186.

Restle, J., Neumann, M., Alves Filho, D.C., Pascoal, L.L., Rosa, J.R.P., Menezes, L.F.G. e Pelegrinni, L.G. 2001. Terminação em confinamento de vacas e novilhas sob dietas com ou sem monensina sódica. Rev. Bras. Zootecn., 30: 1801-1812.

Ribeiro, F.G., Leme, P.R., Bulle, M.L.M., Lima, C.G., Silva, S.L., Pereira, A.S.C. e Lanna, D.P.D. 2002. Características de carcaça e qualidade de carne de tourinhos alimentados com dietas de alto concentrado. Rev. Bras. Zootecn., 31: 749-756. Richardson, L.F., Raun, A.P., Potter, E.L., Cooley,
C.O. and Rathmacher, R.P. 1976. Effects of monensin on rumen fermentation in vitro and in vivo. J. Anim Sci., 43: 657-664.

SAS. 1998. SAS/STAT User's Guide. Release 7.0. SAS Institute. Cary, NC. 441 pp.

Van Soest, P.J., Robertson, J.B. and Lewis, B.A. 1991. Methods for dietary, fiber, neutral detergent fiber, and nonstarch polysaccharides in relation to animal nutrition. J. Dairy Sci., 74: 3583-3597.

Waldrip, H.M. and Martin, S.A. 1993. Effects of an Aspergillus oryzae fermentation extract and other factors on lactate utilization by the ruminal bacterium Megasphaera elsdenii. J. Anim. Sci., 71: 2770-2776.

Wallace, R.J. 1994. Ruminal microbiology, biotechnology and ruminant nutrition: progress and problems. J. Anim Sci., 72: 2992-3003.

Wegener, H.C. 2003. Antibiotics in animal feed and their role in resistance development. Curr. Opin. Microbiol., 6: 439-445.

Weiss, W.P., Conrad, H.R. and St Pierre, N.R. 1992. A theoretical-based model for predicting total digestible nutrient values of forages and concentrates. Anim. Feed Sci. Tech., 57: 717-726.

Williams, P.E.V., Tait, C.A.G., Innes, G.M. and Newbold, C.J. 1991. Effects of the inclusion of yeast culture (Saccharomyces cerevisiae plus growth medium) in the diet of dairy cows on milk yield and forage degradation and fermentation patterns in the rumen of steers. J. Anim. Sci., 69: 3016-3026.

Wohlt, J.E., Finkelstein, A.D. and Chung, C.H. 1991. Yeast culture to improve intake, nutrient digestibility and performance by dairy cattle during early lactation. J. Dairy Sci., 74: 13951400.

Zinn, R.A., Plascencia, A. and Barajas, R. 1994. Interaction of forage level and monensin in diets for feedlot cattle on growth performance and digestive function. J. Anim. Sci., 72: 22092215. 